\title{
\#WaysToRelax: developing an online alcohol- related health promotion animation for people aged 55 and older
}

\author{
Nyssa Ferguson ${ }^{a}$, Michael Savic ${ }^{a, b, c}$, Victoria Manning ${ }^{a, b}$ and \\ Dan I Lubman ${ }^{a, b}$ \\ a Turning Point, Eastern Health, Melbourne, Victoria, Australia \\ b Eastern Health Clinical School, Monash University, Melbourne, Victoria, Australia \\ c Corresponding author: michaels@turningpoint.org.au
}

\section{Article history}

Publication date: April 2017

Ferguson N, Savic M, Manning V, Lubman DI. \#WaysToRelax: developing an online alcohol-related health promotion animation for people aged 55 and older. Public Health Res Pract. 2017;27(2):e2721718. doi: http://dx.doi. org/10.17061/phrp2721718

\section{Key points}

- We developed a health promotion animation based on qualitative research that found that people aged 55 and older often use alcohol to relax and manage stress

- This project highlights the need for nove health promotion approaches based on the experiences of people aged 55 and older

- A research-into-action approach might be useful in developing appropriate and appealing health promotion responses

\section{Abstract}

Alcohol use among middle-aged and older adults (55 years and older) is increasingly becoming a public health concern. Despite this, there is relatively little research on the experiences of alcohol use and related concerns among people aged 55 and older to inform tailored and engaging health promotion activities. To address this gap, we aimed to develop an engaging alcoholrelated health promotion resource for people aged 55 and older. We drew on a research-into-action approach, which involved: 1) thematic analysis of alcohol-related concerns in online counselling transcripts of 70 people aged 55 and older, 2) a review of health promotion literature, and 3) consultation with consumers of alcohol and other drug services, and carers.

The research phase highlighted that people aged 55 and older were concerned that their reliance on alcohol use to manage stress had become a habit they wanted to shift. Alongside this, the literature showed that people aged 55 and older were often dismissive of conventional health promotion activities, and pointed to the benefits of conveying health promotion messages through animation.

In response, we developed an animation to stimulate reflection and thought about other ways to relax and manage stress. We drew on health promotion principles to ensure that the animation had a positive message and was engaging without being ageist or paternalistic. It was further refined with input from consumers and carers, who thought the animation was appropriate, appealing and useful. Future activities will include further dissemination and evaluation of the animation and associated activities. 


\section{Introduction}

Alcohol use among middle-aged and older adults (55 years and older) has been overshadowed by a focus on young people, despite research indicating steady increases in the amount of alcohol consumed by people aged 55 and older. ${ }^{1}$ Recent data suggest that rates of risky drinking have also increased among people aged 55-64 in Australia. ${ }^{2}$ People older than 50 are the most likely of any age group to abstain from alcohol use; however, data indicate that they are also the most likely to be daily drinkers. ${ }^{3}$ Furthermore, recent data indicate that people in their 40 s and 50 s are the most likely to regularly consume five or more standard drinks during a drinking occasion. ${ }^{4}$

Despite this, health promotion activities to address risky alcohol consumption among people aged 55 and older are lacking. ${ }^{5}$ Australia's ageing population is predicted to double during the next 40 years $^{6}$, so risky alcohol use in this age group is likely to place an increasing burden on healthcare systems. As such, appropriate prevention strategies are needed. At present, most prevention strategies and campaigns targeting older adults focus on particular diseases affecting this age group, such as stroke and cardiovascular diseases. ${ }^{5}$ There is a need for novel and engaging age-appropriate health promotion activities to reflect the needs of this age group that are not solely focused on pathologies and are not 'preachy'. 7

Even though internet use by people aged 55 and older is common ${ }^{8}$, there are relatively few online health promotion activities targeting this group. Given the accessibility of the medium and the lack of appropriate alcohol-related health promotion material targeted at people aged 55 and older, we aimed to develop an engaging online health promotion animation for this group to increase awareness of alternative avenues of managing stress that do not involve alcohol. The animation was designed to be housed on the Counselling Online website as the first in a suite of engaging and practical self-help resources for adults concerned about their alcohol and other drug use. In this article, we describe the researchinto-action development process and reflect on wider implications for health promotion practice.

\section{Research on the alcohol-related concerns of people aged 55 and older}

To understand the alcohol-related concerns of people aged 55 years and older, and identify prevention opportunities, we undertook a qualitative analysis of online counselling transcripts involving people in this age group. Counselling Online (www.counsellingonline.org.au) is a free national $24 / 7$ online counselling service for alcohol and other drug problems, which delivers more than 4000 counselling episodes each year. Counselling Online provided 70 de-identified transcripts of counselling sessions that took place between 2012 and 2016. Clients often discuss their reasons for, and concerns relating to, alcohol and other drug use, and counsellors often suggest self-help strategies, so we considered transcripts a useful data source for needs assessment and for informing the development of health promotion resources. The project was approved by the Eastern Health Human Research Ethics Committee (approval number: LR53-1112).

In our sample, $62.9 \%$ of participants were aged 55-59, 25.7\% were 60-64, and 11.4\% were older than 65. Most were female (67.1\%), were born in Australia (87.2\%), identified as heterosexual (95.2\%), had sought help for their alcohol use before (54.3\%), and had heard about Counselling Online through the internet (65.7\%). The majority of participants reported drinking daily (70\%) at levels considered risky in Australia's national guidelines (five or more standard drinks on an occasion). ${ }^{9}$

We conducted a thematic analysis using the Framework approach ${ }^{10}$ to identify common alcoholrelated concerns and experiences in transcripts. This involved coding data into common themes, developing a thematic framework and then charting relationships within and between themes. ${ }^{10}$ As per the Framework approach, coding and development of a thematic framework were based on themes that emerged from the data inductively, as well as being guided by the aims of the research in a more deductive fashion. ${ }^{10}$ For the purposes of this article, we focus on three major themes that emerged and informed the development of a health promotion animation: 1) using alcohol to relax and cope with stress, 2) types of concerns about alcohol and 3) self-help strategies.

\section{Using alcohol to relax and cope with stress}

People aged 55 and older reported multiple and diverse reasons for using alcohol, including social reasons, pleasure and habit. However, using alcohol to relax and cope with stress or other issues was the most commonly reported reason. Participants discussed several factors that contributed to stress, including work, physical and mental health issues, bereavement, financial issues, and life events such as anxiety about the transition to retirement. Given the diverse range of stressors that people aged 55 and older reported facing, we identified "developing new ways to cope with stress" as a useful focal point for our animation. The first few scenes of the animation refer to some of the stressors mentioned by participants by posing questions such as "Busy day? Stressed? Time to unwind?"

\section{Types of concerns about alcohol}

Alcohol was seen as a way of alleviating or escaping stress; however, reliance on alcohol to relax and its 
undesirable impacts were also major causes for concern among participants.

Some were also worried that habitual use of alcohol to relax was hard to control or shift, and was having unwanted effects on their health, wellbeing and relationships. Many participants expressed a desire to break their habit and reduce their alcohol use as a way of improving broader health and wellbeing. We attempted to speak to these concerns and desires in our animation by posing the question "Is that bottle of wine more trouble than it's worth?" while acknowledging that "sometimes it's difficult to make a change".

\section{Self-help strategies}

Counsellors responded to participants' concerns in various ways, but the most common response was to elicit and provide suggestions about self-help strategies that people might try. As well as more general harm-reduction strategies, strategies coproduced by counsellors and participants predominantly revolved around ways to shift habits and alternative ways to manage stress.

Similarly, through discussion with participants, counsellors often encouraged people to "experiment" and find "new ways to relax that don't involve alcohol". This stimulated further discussion and reflection from participants, who spoke about particular activities and new ways to relax that might work for them, such as sport or watching a film. These were incorporated into the animation as examples. Because suggestions were coproduced, many participants indicated that they would try to develop some of these new ways to relax. We wanted our animation to reassure participants and help to stimulate reflection on activities that might help people relax, in the same way that counsellors did. For example, after acknowledging the challenges of making a change, we invite reflection in the animation by saying "Step back, take a moment and think about what else has helped you relax".

In light of other research that reiterates that people aged 55 and older use alcohol to manage stress and relax $^{1,11}$, and are concerned about the impacts of habitual use $^{1}$, our findings provided a strong justification to focus our health promotion efforts on alternative ways of managing stress and relaxing as a way of shifting unwanted habits. This is also relevant given the potential increases in free time and reduced responsibilities that can accompany retirement and other lifestyle changes among older adults. ${ }^{5}$

\section{Research into action: developing} the animation

We used the findings from the qualitative research about participants' desire to develop new ways to relax, alongside health promotion principles, to develop a draft of the animation, which we then refined through feedback and consultation (Figure 1). We decided to develop an animation rather than more conventional fact sheets or other written materials because middle-aged and older adults may be sceptical about traditional alcohol-related health promotion resources and campaigns. ${ }^{1}$ Animation is "typically perceived as non-threatening, familiar and accessible across age groups, cultures and literacy levels" ${ }^{2}$, and allows greater control over representation of characters and concepts than live-action films. ${ }^{13}$

Figure 1. Animation development process

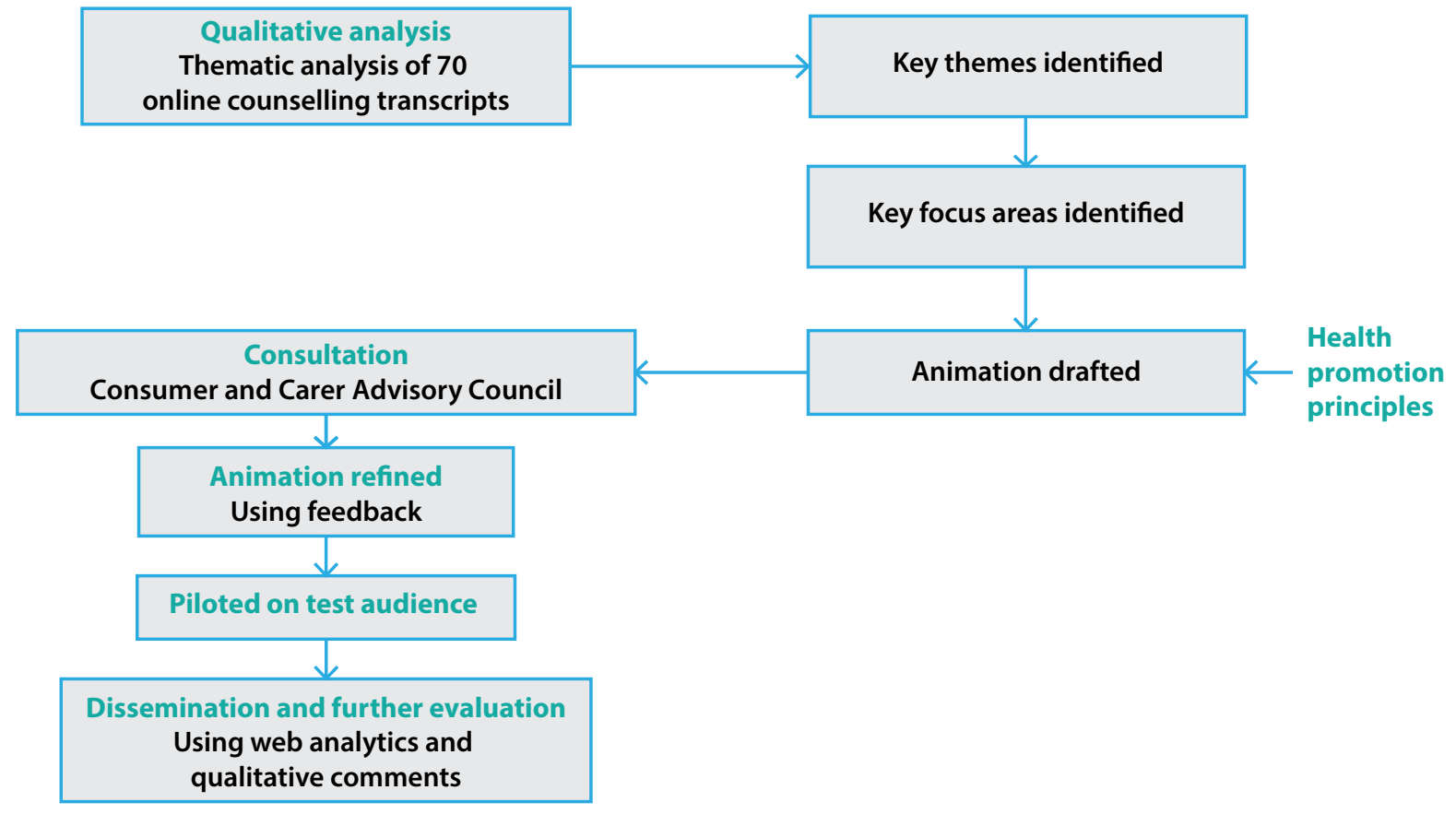


Consequently, animation has been found to be an effective way of delivering health-related information. ${ }^{14-15}$ It is thought to have benefits over conventional health promotion materials by maintaining the attention of the target audience and improving information recall. ${ }^{12}$

In delivering key messages, we drew on health promotion principles and research relevant to people aged 55 and older. Wilkinson and Dare ${ }^{16}$ argue that public health responses need to be holistic in perspective and acknowledge the complex role that alcohol plays in the lives of older adults, including the psychosocial benefits derived from alcohol consumption. ${ }^{16}$ Our messaging was also guided by recommendations that health promotion responses among older adults should be "age appropriate, age specific, not to be open to interpretation as paternalistic or ageist, and better reflect the drinking practices of this group". ${ }^{7}$ As such, the animation was designed to specifically avoid the 'heavy-handed' approach that people aged 55 and older have been shown to be dismissive of. ${ }^{1}$ For example, the middle-aged and older adults interviewed in the study by Haighton et al. ${ }^{1}$ were aware of alcohol-related health campaigns and guidelines, but perceived these as being irrelevant or 'preachy'.

We drew on positive messaging and incorporated humour - both of which have been shown to be useful in engaging people aged 55 and older in behaviour change c7,18 $^{17}$ to motivate individuals to find their own strategies to manage stress without relying on alcohol. The animation was developed in PowToon, an easy-to-use and low-cost animation development program that uses precreated images. We were careful to select 'neutral' images and activities to avoid unhelpful stereotyping of people aged 55 and older (as well as avoiding problematic gendered norms). The \#WaysToRelax hashtag was used at the end of the animation to reiterate the key message and invite active participation from the target audience through social media.

To refine and strengthen the animation, we consulted the Turning Point Consumer and Carer Advisory Council, a group of individuals, family members and carers of people with lived experience of alcohol and other drug issues, many of whom were in the target age range. We asked for feedback on the animation's acceptability and usefulness, and suggestions for improvement around messaging, images, pacing and general design. The animation was generally well received. The group commented that the humour, pace and messaging were effective and sensitive. Other elements such as colour palette and images were adjusted according to feedback. For instance, the draft animation used a lot of yellow, and members of the group said this was not a particularly relaxing colour, so we changed it to a softer blue. After editing, the draft was further piloted on a test audience. The animation was initially distributed through the Counselling Online website, the Turning Point YouTube channel (youtu.be/Uzxb3EoUa1A) and social media.
In terms of further dissemination and associated activities, we plan to evaluate the animation, develop additional research-informed animations and incorporate these into a suite of self-help resources on the Counselling Online website. \#WaysToRelax could also potentially form the basis of a health promotion campaign to promote active participation from the target audience, and generate additional shareable content such as stories, photos and videos about ways people relax.

\section{Conclusions and implications for health promotion practice}

This project reiterates the need for engaging and novel health promotion approaches with people aged 55 and older. Consistent with other research $1,17,18$, consultations with consumers and carers highlighted key elements that might resonate with people in this age group. Rather than overly prescriptive, ageist or paternalistic messaging that simply focuses on the harms of alcohol use, more creative, humorous and playful content might be better received. ${ }^{7}$ Such messaging is likely to reflect a respect for older people as individuals, and incorporate concerns that resonate more with older people's lifestyles and sensibilities. ${ }^{7}$

Using a research-into-action approach and involving people aged 55 and older in resource development may be useful to ensure that responses are appropriately tailored to this population. As we have shown, the qualitative analysis provided an empirically derived message and focus for our health promotion animation. Involving consumers and carers in the development of the animation was also critical to ensure that we conveyed our message in a sensitive and engaging way.

The research-into-action approach and lessons learnt might be useful in informing future health promotion work with middle-aged and older adults. A critical next step in the process will be to formally evaluate the effectiveness of the animation and associated activities, to inform the development of future resources.

\section{Acknowledgements}

This project was funded by the Lord Mayor's Charitable Foundation. Thanks to Emma Sandral and Gabriel Francis for assisting with coding of transcripts and Fiona Blee and Barbara Hunter for input in the early stages of this project. We are also grateful to the members of the Turning Point Consumer and Carer Advisory Council for valuable input into the development of the animation, as well as Rick Loos and Cassandra Jovic for helpful feedback on the animation.

\section{Competing interests}

None declared 


\section{Author contributions}

NF contributed to project design, literature review, coding, animation development and writing the manuscript. MS contributed to project design, coding and qualitative analysis, consultation and writing the manuscript. VM and DIL contributed to project design, and writing and editing the manuscript. All authors read and approved the final manuscript.

\section{References}

1. Haighton C, Wilson G, Ling J, McCabe K, Crosland A, Kaner E. A qualitative study of service provision for alcohol related health issues in mid to later life. PloS one. 2016;11(2):e0148601.

2. Australian Bureau of Statistics (ABS). Gender indicators, Australia, Jan 2013: Consumption of alcohol. Canberra: ABS; 2013 [cited 2017 Mar 8]. Available from: www.abs. gov.au/ausstats/abs@.nsf/Lookup/4125.0main+features33 10Jan\%202013

3. National Centre for Education and Training on Addiction. Secondary analysis of 2010 National Drug Strategy Household Survey. Adelaide: NCETA; 2013.

4. Australian Institute of Health and Welfare. National Drug Strategy Household Survey 2013. Canberra: AlHW; 2014 [cited 2016 Dec 19]. Available from: www.aihw.gov.au/ WorkArea/DownloadAsset.aspx?id=60129549848

5. Hunter B. Older people and alcohol and other drugs. 2011 Melbourne: Australian Drug Foundation; 2013 [cited 2017 Mar 8]. Available from: adf.org.au/wp-content/ uploads/2017/02/ADF-PRQ-Aug11.pdf

6. Commonwealth of Australia. Australia to 2050: future challenges. Canberra: Commonwealth of Australia; 2010 [cited 2017 Mar 8]. Available from: archive.treasury.gov. au/igr/igr2010/Overview/pdf/IGR_2010_Overview.pdf

7. Wilkinson C, Dare J, Water S. An exploration of how social context and type of living arrangement are linked to alcohol consumption among Australians. Canberra: Foundation for Alcohol Research \& Education; 2012 [cited 2017 Mar 8]. Available from: fare.org.au/wpcontent/uploads/research/FARE-Final-Report-Wilkinsonet-al-2012.pdf

8. VicHealth. Technology and older people: findings from the VicHealth Indicators Survey, research highlights. Melbourne: Victorian Health Promotion Foundation; 2013 [cited 2017 Mar 8]. Available from: www.vichealth.vic.gov. au/ /media/ResourceCentre/PublicationsandResources/ Research/Technology-older-people-research-summaryOct2013.pdf?la=en
9. National Health and Medical Research Council. Australian guidelines to reduce health risks from drinking alcohol. Canberra: Commonwealth of Australia; 2009 [cited 2017 Mar 8]. Available from: www.nhmrc.gov.au/_ files_nhmrc/publications/attachments/ds10-alcohol.pdf

10. Ritchie J, Spencer L. Qualitative data analysis for applied policy research. In: Bryman A, Burgess RG, editors. Analyzing qualitative data. London: Routledge; 1994. p. 173-94.

11. Dare J, Wilkinson C, Allsop S, Waters S, McHale S. Social engagement, setting and alcohol use among a sample of older Australians. Health Soc Care Community. 2014;22(5):524-32.

12. George S, Moran E, Duran N, Jenders RA. Using animation as an information tool to advance health research literacy among minority participants. AMIA Annu Symp Proc. 2013;2013:475-84.

13. Champoux JE. Comparative analyses of live-action and animated film remake scenes: finding alternative film-based teaching resources. Educ Media Int. 2005;42(1):49-69.

14. Calderón JL, Shaheen M, Hays RD, Fleming ES, Norris KC, Baker RS. Improving diabetes health literacy by animation. Diab Educ. 2014;40(3):361-71.

15. Schnellinger M, Finkelstein M, Thygeson MV, Vander Velden H, Karpas A, Madhok M. Animated video vs pamphlet: comparing the success of educating parents about proper antibiotic use. Pediatrics. 2010;125(5):990-6.

16. Wilkinson C, Dare J. Shades of grey: the need for multidisciplinary approach to research investigating alcohol and ageing. J Public Health Res. 2014;3:180

17. Cernerud L, Olsson $\mathrm{H}$. Humour seen from a public health perspective. Scand J Public Health. 2004;32(5):396-8.

18. Notthoff N, Carstensen L. Positive messaging promotes walking in older adults. Psychol Aging. 2014;29(2):329-41.

\section{Copyright: (c) (ㅇ)(2)}

(C) 2017 Ferguson et al. This article is licensed under the Creative Commons Attribution-NonCommercial-ShareAlike 4.0 International Licence, which allows others to redistribute, adapt and share this work non-commercially provided they attribute the work and any adapted version of it is distributed under the same Creative Commons licence terms. See: www.creativecommons.org/licenses/by-nc-sa/4.0/ 